\title{
Sandro Gallazzi
}

\section{A sabedoria e a lei que subsiste para sempre $(\mathrm{Br} 1,4)$}

\begin{abstract}
Resumo: 0 livro de Baruc traz até nós o pensamento das comunidades judaicas da diáspora. De maneira especial reflete sua preocupação de conviver em paz com os impérios nos quais as comunidades estavam espalhadas e nos aproxima do elemento universal e catalisador, capaz de identificar e de unificar este povo disperso entre as nações. 0 templo permanece como realidade simbólica. 0 livro, porém, aparece como a presença entre nós da sabedoria de Deus.
\end{abstract}

Palavras-chave: Diáspora, Sabedoria, Pós-exílio, Templo

\begin{abstract}
The book of Baruch brings to us the thoughts of Jewish communities in the diaspora. In a special way, it reflects their concern to live in peace with the empires, in which the communities were dispersed, and bring us closer to a universal and catalytic element, capable of identifying and unifying this dispersed people among the nations. The temple remains a symbolic reality. The book, however, appears as the presence among us of the wisdom of God.
\end{abstract}

Keywords: Diaspora, Wisdom, Post exile, Temple

O livrinho de Baruc pode ser considerado, junto com o livro de Tobias, um vade-mécum do bom judeu que vive na diáspora de Babilônia.

0 fato de não termos um eventual texto hebraico original é mais uma confirmação desta hipótese. É verdade que este livro se apresenta como um escrito direcionado "ao sacerdote Joaquim filho de Helcias, filho de Salom, aos outros sacerdotes e a todo o povo que se achava com ele em Jerusalém" (1,7), com a sugestão de ler "este livro, que vos mandamos para ser lido em público, na casa do Senhor, no dia da Festa e nos dias oportunos" $(1,14)$. Apesar disso, é possível que este texto não tenha recebido a esperada importância nas terras de Judá. É o que disse, também, São Jerônimo que não quis fazer a tradução latina, pois "os hebreus nem liam nem possuíam este livro"1.

Precisamos, porém, considerar que o livro de Baruc consta na versão de Teodocião que só inclui textos traduzidos do hebreu ou do aramaico. 
As discussões entre os estudiosos concordam em algum ponto:

Apesar do que está escrito $(1,1)$, o autor deste texto não é Baruc, o discípulo de Jeremias. É mais um caso evidente de pseudonímia.

Trata-se, provavelmente, de uma coleção de textos que existiam anteriormente em forma separada e heterogênea: uma oração penitencial $(1,15-3,8)$, uma reflexão sobre a sabedoria $(3,9-4,4)$ e um poema de encorajamento a Jerusalém $(4,5-5,9)$. Estes textos podem ter sido reunidos, na metade de secundo século aec, num livreto contemporâneo ao conflito com Antioco IV e a purificação do templo, operada por Judas Macabeu. Os paralelismos com a oração penitencial do livro de Daniel (Dn 9) e com o hino de exaltação da sabedoria do livro do Sirácida (Eclo 24), sugerem esta data como a da composição final.

As informações contidas no livro nos ajudam a compreender a realidade vivida pelos judeus da diáspora.

O grupo que pensou e produziu estas palavras vive nas terras de Babilônia e é formado pelos descendentes da elite judaíta levada ao cativeiro em 597 aec, "depois que Nabucodonosor, rei da Babilônia, deportou Jeconias, os príncipes, os serralheiros, os grandes e o povo da terra ${ }^{2}$, levando-os de Jerusalém para a Babilônia" $(1,9)$. Eram os exilados com os quais estava Ezequiel. Entre seus descendentes encontraremos, mais tarde, Esdras e Neemias. Aliás, várias são as semelhanças entre Baruc e Esdras.

É um grupo que pode se reunir em assembleia, que tem chefes e autoridades $(1,4)$, que pode celebrar pública e comunitariamente $(1,5)$ e que, possivelmente está vivendo numa colônia agrícola, nas terras irrigadas de Babilônia $(1,4)$ e que tem uma vida economicamente ativa e independente.

0 fato de este grupo poder "coletar dinheiro, segundo as posses de cada um" $(1,6)$ e de recuperar "para restituí-los à terra de Judá, os utensílios da casa do Senhor" $(1,8)$ indicam que o cativeiro já terminou e que a menção posterior a Nabucodonosor e a seu filho Baltazar $^{3}(1,11)$ é simbólica de qualquer poder imperial, assim como no livro de Judite (Jd 1,1) e no livro de Daniel (Dn 2,1), textos contemporâneos ao de Baruc.

Povo da terra, como sabemos, era a nobreza fundiária que perdeu seus terrenos ao ser deportada (Jr 1,18; 34,8-22; 37,2; 44,21; 52,6).

3 Em nenhum documento histórico Baltazar aparece como filho de Nabucodonosor. Ele era filho do último rei de Babilônia Nabonides que o deixou no governo enquanto guerreava com os persas. Trata-se, então, do primeiro e do último rei de Babilônia, símbolo, assim, de todo o cativeiro e sinal de que quem escreveu o fez bem mais tarde. 
Esta consideração nos ajuda a identificar a presença de um conflito evidente entre os próprios textos bíblicos acima citados. No enquanto os livros de Daniel e de Judite fazem uma leitura crítica, irônica e negativa de Nabucodonosor, o livro de Baruc, assim como os livros de Esdras e Neemias, apresenta uma atitude de subserviência ao império.

Mesmo colocando em destaque "os caldeus se apoderaram de Jerusalém e a incendiaram" $(1,2)$ e a deportação dos exilados operada por Nabucodonosor $(1,9)$, os judeus da diáspora resolvem mandar dinheiro a Jerusalém "a fim de comprardes com ele vítimas para os holocaustos e sacrifícios de expiação e também incenso: Preparai oblações e levai-as a a altar do Senhor nosso Deus. Rogai pela vida de Nabucodonosor, rei da Babilônia, e pela vida de Baltazar, seu filho, para que seus dias sobre a terra sejam como os dias do céu. E o Senhor nos dará força e iluminará nossos olhos, para vivermos à sombra de Nabucodonosor, rei da Babilônia, e à sombra de Baltazar, seu filho; para que os sirvamos por muito tempo e encontremos graça diante deles" (1,10-12).

Nenhuma restrição diante do império opressor; só uma atitude de aceitação e de submissão. 0 templo, alimentado com as ofertas vinda de Babilônia, é colocado a serviço do rei. Uma prece para que os imperadores tenham vida longa e uma prece para ter força para viver à sombra do rei e servi-lo por muito tempo encontrando graça a seus olhos.

Assemelha-se a um eco das palavras de Esdras, o escriba que trouxe a Judá a "lei de Deus que é a lei do rei" (Esd 7,26), levando consigo "a oferenda voluntária do povo" (Esd 7,16) junto com os recursos imperiais e os utensílios a serem recolocados na casa de Deus (Esd $7,19)$, com incumbência de rezar para que não "sobrevenha a ira sobre o reino, sobre o rei e seus filhos" (Esd 7,23).

Bendito seja o SENHOR Deus de nossos pais, que tal inspirou ao coração do rei, para ornar a casa do SENHOR, que está em Jerusalém. E que estendeu para mim a sua benignidade perante o rei e os seus conselheiros e todos os príncipes poderosos do rei. (Esd 7,27)

\section{A situação econômica}

Um grupo, então, que era economicamente tranquilo. Muitos judeus seguiram o conselho de Jeremias (Jr 29,5s) e, em Babilônia, formaram sua família, compraram seu terreno numa terra que era bem mais fértil do que a da Judéia. Muitos procuraram emprego nas cidades, sobretudo no comércio e até na carreira administrativa. Alguns judeus chegaram 
a ser funcionários bem colocados dentro da administração imperial (Est 2,21; Dn 2,48; 6,3; Ne 1,11b; Esd 7,14).

Muitos deles tinham conseguido ficar ricos. Esd 2,69 e Ne 7,71 lembram as ofertas que os judeus deram, quando um grupo deles voltou para Jerusalém. São quantias vultosas: 61.000 dracmas de ouro: cerca de 250 quilos!

E a situação deve ter melhorado ainda mais, pois, um século depois, quando Esdras foi para Jerusalém, com outro grupo, ele levou as ofertas dos judeus de Babilônia: 100 talentos de ouro (3.420 quilos!) e 650 talentos de prata (Esd 8,26).

\section{A situação política}

Ao descrever este grupo, Baruc diz: "somos apenas um pequeno resto entre as nações, por onde nos dispersaste" $(2,13)$. Espalhados dentro do imenso império persa e, depois, grego, os judeus não passavam de pequenos grupos sem maior significação política: uma pequena minoria que vivia dentro da poderosa e intocável máquina burocrática imperial.

Não havia nenhuma possibilidade política de mudar esta situação ou de acabar com esta dominação. 0 conselho dado por Jeremias parecia ser mesmo o mais razoável: "Procurai a paz da cidade onde eu vos deportei" (Jr 29,7).

O judeu se preocupa de estabelecer um relacionamento pacífico de "convivência" com a sociedade envolvente. Eles aceitam mansamente a situação de escravidão $($ Est 7,4$)$ e procuram viver da melhor maneira possível, amparados por uma política imperial que quase sempre lhes foi favorável.

Os judeus da diáspora tornam-se um grupo politicamente confiável e colaborador, que procurou se integrar, da melhor maneira, na estrutura existente, sem perder, porém, sua identidade cultural e religiosa. Eles eram muito bem considerados e valorizados pelos reis gregos. Em vários casos os judeus se colocaram claramente a serviço do império grego. Sua conhecida fidelidade é relembrada oficialmente pelo rei Antíoco III.

Estou persuadido de que os judeus serão bons guardiões de nossos interesses, por causa de sua piedade para com Deus e sei que meus antepassados conheceram a sua fidelidade e a sua pronta obediência às ordens recebidas... a eles prometemos que poderão viver de acordo com suas próprias leis (AJ 12,147-153) . 


\section{A situação social}

Os judeus da diáspora formavam um grupo bem definido. Um grupo fechado, que cultivava fortes vínculos de solidariedade interna. Grande importância era dada à pureza racial, provada pela genealogia.

Criou-se uma situação aparentemente contraditória. 0 grupo é fechado e, no mesmo tempo, "espalhado"; procura conviver com o sistema, mas segue suas próprias leis que "não se parecem com as de nenhum outro povo" (Est 3,8). Relacionam-se com todos, mas casam só entre si. Não possuem um território próprio, mas cultivam um nacionalismo muito forte.

Esta ambiguidade aparece com muita força no texto de Baruc. Se, de um lado, o grupo suplica "faze que obtenhamos graça diante daqueles que nos deportaram" $(2,14)$, do outro, eles sabem que "o Senhor os entregou ao domínio de todos os reinos que nos cercam, para serem objeto de opróbrio e exemplo de desolação no meio de todos os povos vizinhos, entre os quais o Senhor os dispersou" $(2,4)$. Esta ambiguidade alcança o ponto mais alto quando chega a afirmar:

"Eis o que diz o Senhor: Curvai vosso dorso e servi ao rei da Babilônia, assim continuareis a morar na terra que dei a vossos pais". $(2,21)$

O cativeiro aconteceu porque não foi obedecida a ordem do Senhor de servir ao rei de Babilônia. E eis que, agora, "tornaram-se escravos, em vez de senhores, porque pecamos contra o Senhor nosso Deus, deixando de ouvir sua voz" $(2,5)$.

\section{A resposta do livro de Baruc}

A realidade da diáspora leva as comunidades judaicas a refletir e a buscar novas formas de viver sua fé e de encarar a nova situação que se criou para quem decidiu viver fora da terra de Israel.

O livro de Baruc, seguindo o livro de Ezequiel que profetizou a este grupo quando estava no exílio, marca os passos desta reflexão.

\section{a. O vínculo com o templo de Jerusalém}

Não se pode erguer um templo a Iahweh em terra estrangeira ${ }^{4}$. É preciso, então, manter o vínculo com o templo de Jerusalém. Baruc

Isso só aconteceu no Egito: houve em Elefantina um antigo templo do culto pré-josiânico e, mais tarde, foi erguido um templo em Leontópolis, quando o sumo sacerdote Onias III foi assassinado e o seu filho fugiu para o Egito. Estaríamos, então, na mesma época da redação final do livro de Baruc. 
testemunha esta relação: uma carta, umas ofertas em dinheiro, uma sugestão de prece. As ofertas são para os holocaustos, os sacrifícios de expiação, o incenso e as oblações $(1,10)$ : ações próprias dos sacerdotes aos quais as ofertas são destinadas $(1,7)$.

Há, porém, uma nova forma de celebração: “Eles choraram, jejuaram e ergueram súplicas ao Senhor" $(1,5)^{5}$. A distância do templo de Jerusalém leva as comunidades da diáspora a encontrar gestos de comunhão com os sacrifícios realizados em Jerusalém. São as "obras de piedade": o jejum "substitui" os holocaustos, a esmola os sacrifícios pacíficos e a oração a queima do incenso matutino e vespertino. Estas obras de piedade ${ }^{6}$ viraram prática costumeira nas comunidades que viviam longe de Jerusalém (Mt 6,1-18).

A comunhão com as celebrações do templo de Jerusalém, sempre está no horizonte destas comunidades (Dn 6,10). 0 livro de Baruc deve ser lido durante a celebração: "Lede este livro, que vos mandamos para ser lido em público, na casa do Senhor, no dia da Festa ${ }^{7}$ e nos dias oportunos" $(1,14)$.

\section{b. A oração penitencial}

Era preciso que as comunidades da diáspora explicassem para si o porquê da mesma. Não podia ser entendida como uma derrota de Iahweh por parte dos deuses de Babilônia, segundo a normal explicação dada pelas populações da região. Ezequiel foi quem melhor explicou esta realidade: "Farei com que caia sobre tua cabeça o teu comportamento - oráculo do Senhor Iahweh" (Ez 16,43). 0 exílio e a diáspora posterior são vistas como justo e devido castigo de Deus e, ao mesmo tempo, como momento favorável de conversão e de formação de um povo purificado e renovado que saberá, de agora em diante, observar os mandamentos de Deus (2, 31-33; Ez 36-37).

A oração penitencial é parte integrante do livro de Baruc $(1,15$ $3,8)$. Uma leitura atenta pode encontrar nela um conjunto de afirmações costumeiras e comuns a outros salmos e a outras orações penitenciais presentes nos textos bíblicos. Os paralelismos mais significativos são

O jejum, como celebração coletiva, só aparece em textos pós-exílicos. Jz 20,26 e 2Sm 7,6 são acréscimos tardios, marcados pelo sujeito, eminentemente pos-exílico, "filhos de Israel". Pelo resto, o jejum era uma prática individual, sobretudo, em caso de luto (2Sm 15-24).

6 É a respeito destas obras que Paulo polemiza quando afirma que o que conta é a fé e não as obras.

Trata-se, muito provavelmente, da festa das Tendas, a mais importante festa celebrada no pósexílio. 
com as orações penitenciais de Esdras (9,6-15), do capítulo nove de Neemias, do texto grego de Daniel (9,4-19) e do Salmo 106.

É uma releitura em chave penitencial da história do povo que "desde o dia em que o Senhor tirou nossos pais do Egito, até hoje, temos sido desobedientes ao Senhor nosso Deus, e procedemos levianamente, deixando de ouvir sua voz" $(1,19)$. A situação atual é a consequência deste proceder.

Em destaque, sobretudo, está a afirmação que norteará toda a releitura deuteronomista da história de Judá e de Israel: "Não escutamos a voz do Senhor nosso Deus, transmitida por todos os profetas que nos enviou" $(1,21)$. Porém, a única desobediência à palavra profética que aqui é explicitada é, como vimos:

"Eis o que diz o Senhor: Curvai vosso dorso e servi ao rei da Babilônia, assim continuareis a morar na terra que dei a vossos pais. Se não atenderdes à voz do Senhor, que vos ordena servir ao rei da Babilônia, farei cessar, nas cidades de Judá e em Jerusalém, as exclamações do noivo de alegria e de regozijo, as vozes do noivo e da noiva, e o país inteiro se transformará em deserto, sem habitantes.

Não atendemos a tua ordem de servir ao rei da Babilônia. Cumpriste, então, tuas palavras pronunciadas por intermédio de teus servos, os profetas, predizendo que os ossos de nossos reis e os ossos de nossos pais seriam tirados dos sepulcros (...) Por causa da perversidade da casa de Israel e da casa de Judá, reduziste à miséria, em que hoje se encontra, esta Casa que traz teu nome" (2,21-26).

O único profeta que falou claramente da necessidade de servir ao rei de Babilônia foi Jeremias quando dirigiu a Sedecias as palavras aqui citadas literalmente (Jr 27,12), assim como encontramos, neste trecho, a lembrança de outras palavras de Jeremias: 7,34; 8,1-2; 14,12; $33,10-11 ; 36,30$. De certa forma, parece que Jeremias, através da boca de seu discípulo Baruc, esteja dizendo: eu avisei!

Importante notar que se trata de uma clara orientação de política internacional e que, teoricamente, nada teria a ver com a dimensão religiosa.

As outras "traições" a Iahweh são lembradas de maneira genérica e costumeira:

Não ouvimos a voz do Senhor nosso Deus, que nos exortava a vivermos segundo os mandamentos que o Senhor nos deu $(1,18.21 ; 2,5.10)$.

Nos afastamos, seguindo cada um as inclinações de seu coração perverso, para servir a outros deuses e praticar o mal diante dos olhos do Senhor nosso Deus $(1,22)$. Não fizemos súplicas diante do Senhor, para que cada um se afastasse dos pensamentos de seu coração perverso $(2,8)$ 
Nós agora pecamos, praticamos iniquidades e injustiças contra todos os teus mandamentos, ó Senhor nosso Deus $(2,12)$

Tudo é dito por fórmulas clássicas que caberiam em qualquer ato penitencial. A única fórmula original e específica é aquela relativa ao não ter se rendido ao rei de Babilônia.

Se for correto pensar que a redação final do texto é da época da guerra macabaica, podemos chegar a suspeitar que os judeus da diáspora fossem contrários à guerra que estava sendo travada em Judá, preocupados, talvez, com as consequências negativas que lhes poderiam advir por pertencer ao mesmo povo que estava combatendo contra o imperador, com o qual pretendiam manter relações pacíficas.

O livro de Baruc estaria, então, alertando sobre o que poderia acontecer a Jerusalém no caso da provável vitória do rei grego. A situação do antigo passado poderia vir a se repetir agora: destruição da cidade, desterro, humilhação, escravidão e dispersão.

É como se Baruc dissesse: não façam outra vez o erro que nós fizemos quando não ouvimos as palavras de Jeremias. Vamos procurar viver em paz. Curvai vosso dorso e servi ao rei de Antioquia. E o Senhor nos dará força e iluminará nossos olhos, para vivermos à sombra de Antioco, rei da Grécia, e à sombra de Antioco Eupator, seu filho; para que os sirvamos por muito tempo e encontremos graça diante deles.

Vivam em paz vocês na Judeia, para que possamos viver em paz também nós que vivemos na diáspora ${ }^{8}$.

À denúncia de não ter dado ouvido à voz do Senhor, corresponde à súplica para que o Senhor dê ouvido à prece do povo $(2,14.16 ; 3,2.4)$ e manifeste seu poder de salvação. Sempre parafraseando Ezequiel, a súplica pede que Deus atenda nossos pedidos não porque nós o merecemos, mas: "Salva-nos por causa de ti mesmo e faze que obtenhamos graça diante daqueles que nos deportaram, para que toda a terra saiba que tu és o Senhor nosso Deus, pois teu nome foi dado a Israel e a sua raça" (2,14-15).

Esta possibilidade é considerada, também, pela Tradução Ecumênica da Bíblia em sua introdução ao livro de Baruc. De fato é estranho que a guerra macabaica não tenha tido nenhum apoio dos judeus da diáspora. Pelo contrário, o livro segundo dos Macabeus foi escrito para que os judeus de Alexandria celebrassem, também, a festa da dedicação, memorial da vitória de Judas sobre os gregos (2Mc 1,10-2,18). É interessante ver como este texto segue a mesma metodologia: a memória do que fez e disse Jeremias e o que estava escrito na lei de Moisés. A mensagem, porém é contrária à de Baruc. Não esqueçamos, também, o texto grego de Ester escrito para motivar a festa dos Purim, no dia memorial da vitória contra Nicanor. 0 debate entre judeus da terra e da diáspora em relação ao império deve ter sido grande. 
Assim, com coração renovado e dócil seremos dignos da promessa perene: "Eu, então, os reconduzirei à terra que prometi, com juramento, a seus pais, Abraão, Isaac e Jacó; e dela serão senhores. Eu os multiplicarei e não serão diminuídos. Farei com eles aliança eterna, para que eu seja o seu Deus e eles sejam o meu povo. E não mais tirarei Israel, meu povo, da terra que lhes dei" (2,34-35).

\section{c. A sabedoria e a lei}

A promessa da posse da terra - que era um aspecto essencial da bênção de Iahweh para seu povo - adquire, a partir da diáspora, uma dimensão escatológica. É algo reservado ao futuro ${ }^{9}$.

A bênção de Deus é desligada da posse física da terra. Para os judeus da diáspora a posse da terra não era essencial. Sua economia estava centrada em outras atividades. Isso, aos poucos, irá mudar o próprio rosto de Iahweh e as características do seu projeto.

A mensagem dos antigos profetas era baseada numa palavra chave: fazer a justiça. Era a denúncia de um sistema opressor injusto, na vontade de restabelecer uma ordem política e econômica sobre os pilares da justiça, da partilha, para que não houvesse oprimidos no meio do povo. Para que isso acontecesse, era necessário enfrentar a questão da posse da terra, que devia ser garantida a todos, sem nenhuma exploração.

Fazer justiça, neste sentido, era sociologicamente inviável, para os judeus da diáspora.

Acontece, assim, uma mudança muito significativa: a preocupação, na diáspora, não é tanto a de fazer a justiça, mas a de ser justos.

Esta é a preocupação de boa parte da literatura pós-exílica de cunho sapiencial.

Numa situação de diáspora era preciso encontrar o elemento que, no mesmo tempo, identificasse o grupo e fosse, também, elemento de coesão. Algo como o espírito nacional de um povo sem mais nação ou, usando a linguagem bíblica, como ser "povo" no meio das "nações".

0 templo, mesmo reconstruído, não podia mais ser este elemento catalisador. Não tinha este alcance para quem vivia tão longe e em centros bem mais desenvolvidos. Afinal, na organização imperial, persa, grega ou romana, Judá não era o centro, era "província”. Para os judeus da diáspora o templo era algo mais simbólico do que real.

É possível que a diáspora tenha sido a inspiradora da conclusão do Pentateuco com a morte de Moisés, deixando a terra prometida como um horizonte a ser sempre buscado, mesmo que nem sempre alcançado. 
O lugar central que o templo ocupava na época monárquica, foi tomado pela "Sabedoria", entendida como manifestação suprema de Deus. Uma manifestação que não precisava, pelo contrário, ultrapassava confins e muros, assumindo uma dimensão espacial universal; sabedoria entregue ao único "povo eleito", mesmo espalhado pela terra inteira. A "casa de Deus" passa a ser todo o universo:

Ó Israel, quão grande é a casa de Deus e quão extensa a área de seu domínio! Sim, é vasta e ilimitada, alta e incomensurável (3,24-25).

O livro de Baruc, assim como faz Sirácida no capítulo 24 e na linha de Provérbios 9 e do capítulo 28 do livro de Jó, reafirma esta intuição.

Ao se colocar a pergunta central: "Por que, Israel, por que é que estás no país dos inimigos?” $(3,10)$, a resposta, agora, assume uma conotação diferente da resposta dada na precedente oração penitencial.

É porque abandonaste a fonte da sabedoria $(3,12)$.

Se tivesses andado pelo caminho de Deus,

viverias para sempre na paz.

Aprende onde está a prudência,

onde está a força, onde a inteligência,

para saberes também onde está a longevidade e a vida,

onde está a luz dos olhos e a paz (3,13-14).

Uma sabedoria que é exclusiva de Deus, quase uma hipóstase divina, inalcançável, imperscrutável, cuja característica mais importante é a prudência $(3,9.14 .23 .28)$, a virtude de quem sabe que é pequeno e que pouco pode fazer, a não ser seguir o caminho da sabedoria, do discernimento, da inteligência prática e da reflexão.

É uma sabedoria que não pertence aos "chefes das nações" $(3,16)$, nem aos que acumulam prata e ouro $(3,17)$, nem aos artistas $(3,18)$. As antigas e as novas gerações não puderam alcançar a sabedoria $(3,19-21)$. Nem mesmo os que eram considerados sábios por todos não conheceram seus caminhos $(3,21-23)$. Sabedoria que não foi dada nem mesmo aos antigos heróis mitológicos (3,26-27).

Todos pereceram e foram para o Hades, o Sheol, o mundo das sombras $(3,11.19 .28)$.

Esta sabedoria não está ao alcance da humanidade, não adianta atravessar o mar para encontrá-la ou pagá-la a peso de ouro (3,29-30). 
Ninguém conhece seu caminho,

ninguém descobre suas veredas $(3,31)$.

A sabedoria é um dom, um presente divino, daquele que "tudo sabe e conhece", daquele que "criou a terra" e a quem a luz e as estrelas obedecem (3,32-35).

O nosso Deus, único e incomparável,

Deu-a a Jacó, seu servo,

e a Israel, seu amado.

Depois disto, ela apareceu sobre a terra

e no meio dos homens ela conviveu ${ }^{10}(3,37-38)$.

E aqui Baruc faz o salto qualitativo que está presente, também, em Sirácida:

É ela o livro dos mandamentos de Deus

e a lei que subsiste para sempre.

Todos os que a guardam terão a vida;

os que a desprezam, morrerão.

Volta-te, Jacó, para recebê-la;

caminha para o esplendor, guiando-te por sua luz.

Não entregues a outro a tua glória,

nem teus privilégios a um povo estrangeiro.

Ditosos somos nós, ó Israel,

porque nos foi revelado o que agrada a Deus (4,1-4; Eclo 24,23).

O livro dos mandamentos de Deus, da Lei, da toráh, este é o elemento universal, catalisador que une entre si todas as comunidades judaicas espalhadas nas terras dos impérios e que faz deles um "povo" espalhado, mas diferente de todos.

A revelação do que "agrada a Deus", antes, era mediada pelo Sumo Sacerdote, único que tinha acesso à arca da aliança, lugar privilegiado onde Deus ia comunicar suas ordens para o povo (Êx 25,22). Agora esta revelação é mediada pelo "livro". Se a arca só podia estar (e não estava) em Jerusalém, o livro, agora, pode estar em todas as "casas de reunião", em todas as sinagogas.

O livro se tornará o esteio de sustentação do judeu na diáspora. 0 capítulo 8 do livro de Neemias coloca em destaque a importância dada

\footnotetext{
10 A Vetus Latina, ao traduzir o sujeito passou do feminino para o masculino. Este fato e a semelhança com Jo 1,14 fizeram com que este versículo recebesse uma interpretação messiânica, uma profecia a respeito da encarnação de Jesus.
} 
ao livro, cuja leitura se faz com uma solenidade igual, se não maior, à dos sacrifícios.

A palavra escrita deve ser traduzida e interpretada para que a leitura se torne compreensível $(\mathrm{Ne} 8,8)$. A função do profeta que era de transformar em palavra de Deus os acontecimentos da vida, devagar vai sumindo.

Aparece com muito mais força a função do escriba, do rabino, cuja função é explicar uma palavra que já está escrita no livro. A palavra fica "presa" no livro e o teólogo passa a ter maior autoridade do que o profeta. 0 livro acabou com a profecia.

A sinagoga substitui o templo, o rabino substitui o sacerdote e o profeta "desaparece"11.

Sabedoria é, contemporaneamente, o livro da lei e a sua observância. É preciso observar rigidamente a «lei» de Deus, respeitando seus mandamentos.

A diáspora colocará em destaque a prática do sábado, da circuncisão, das obras de piedade. Serão tomadas seriíssimas providências para defender o grupo de qualquer influência que possa corromper o judeu: serão severamente proibidos os casamentos com estrangeiros e serão estabelecidas normas de pureza legal.

Pela prática desta "lei" o judeu torna-se justo e pode esperar com confiança o dia em que o Senhor libertará o povo.

Adquire maior força a teologia da retribuição individual, pela qual o justo sempre será recompensado com o bem e o ímpio (que não observa a lei) verá cair por terra todos os seus planos e encontrará a ruína (Ez 18).

A fidelidade ao livro torna-se a norma operativa do judeu. 0 livro se torna "lei" e "sabedoria" e nele serão procuradas todas as normas, inclusive as mais minuciosas, que devem reger a vida do judeu.

\section{d. A promessa da restauração $(4,5-5,9)$}

0 compromisso com a observância da lei/sabedoria de Deus conduz as comunidades da diáspora a manter os olhos fixos no horizonte, na esperança, na promessa de uma reconstrução e de uma libertação que Deus operará para nós, em reconhecimento e recompensa da nossa fidelidade à sua lei.

Mais tarde, quando o templo será definitivamente destruído pelas legiões de Tito, subsistirá, com a aprovação dos romanos, o judaísmo rabínico. A escola de Jâmnia será um exemplo disso. Deste judaísmo vão sair o Talmud palestino e o Talmud babilônico que serão normativos para as comunidades da diáspora. 
A palavra final do livro de Baruc mantém fielmente este esquema, comum a todos os textos que, agora sim, adquirem um sabor messiânico em sua dimensão escatológica, quase utópica, não porque impossível, mas porque está sempre mais além de onde nós estamos a marcar passos e a determinar rumos.

De certa forma é uma retomada e um resumo de tudo o que foi dito até aqui. Os passos deste anúncio de esperança são marcados e introduzidos pela palavra "coragem!" $(3,5.21 .27 .30)$

Coragem povo meu, memorial de Israel $(3,5)$

Retoma-se a reflexão que explica o porquê do exílio e da diáspora, colocando em destaque a nossa responsabilidade pelo que aconteceu e a profunda dor de Deus que se viu obrigado a castigar. É o lamento de Jerusalém, na falsa-riga do livro das lamentações:

Tornei-me deserta por causa dos pecados de meus filhos:

desviaram-se da lei de Deus,

desconheceram seus mandamentos,

não andaram pelos caminhos dos preceitos divinos,

afastaram-se das veredas da instrução, que deviam seguir $(4,12-13)$.

Depus as vestes dos dias felizes

e vesti o cilício de minha súplica.

Enquanto viver, clamarei ao Eterno $(4,20)$.

O segundo passo é o chamado à esperança, certos que somos da misericórdia de Deus

Coragem, meus filhos! Invocai a Deus! $(4,21)$

O Eterno - vale a pena ressaltar o uso deste apelido de Deus - fará voltar a Jerusalém os filhos antes dispersos. Sua libertação será a manifestação da glória e do esplendor do Eterno. Daí a consequência "política":

Meus filhos, suportai com paciência

a cólera divina que se abateu sobre vós $(4,25)$.

Continua com um apelo à conversão e à mudança de vida

Coragem, meus filhos! Invocai a Deus! $(4,27)$

Assim como tivestes a ideia de afastar-vos de Deus,

convertei-vos e procurai-o com zelo dez vezes maior $(4,28)$. 
Termina com uma declaração de fidelidade a Jerusalém

Coragem, Jerusalém!

Vai consolar-te aquele que te deu o nome $(4,30)$

Os que se alegraram com sua destruição, que escravizaram e humilharam seus filhos, experimentarão por sua vez a ira de Deus e serão devastados e destruídos (4,31-35).

Jerusalém verá a alegria que vem de Deus.

Eis que voltam os filhos que viste partir.

Voltam, reunidos pela voz do Santo,

desde o oriente até o ocidente,

jubilosos da glória de Deus (4,36-37).

\section{e. Exulta Jerusalém (5,1-9)}

A perícope final, assim como a oração penitencial, é uma retomada, em vários casos ao pé da letra, de afirmações contidas no segundo e no terceiro Isaías. Palavras que alimentaram a esperança dos exilados são, aqui, retomadas numa perspectiva escatológica que, poucos anos mais tarde, depois do fracasso da guerra macabaica, dará espaço a um grande crescimento da literatura apocalíptica.

A veste de glória, o manto da justiça, o diadema da glória serão endossados por Jerusalém, que no seu esplendor, estará no alto monte para ver os filhos voltarem do oriente e do ocidente, "reunidos pela voz do Santo" (5,1-6).

Encontramos figuras que serão retomadas nos textos evangélicos, na boca do precursor, indicando que toda esta esperança foi relida na perspectiva de Jesus de Nazaré.

Deus ordenou que se abaixassem

todos os altos montes e as colinas eternas,

e se enchessem os vales, para aplainar a terra,

a fim de que Israel caminhe com segurança,

sob a glória de Deus (5,7; Mc 1,3; Mt 3,3)).

Ao renascer, Jerusalém terá outro nome que dará plenitude ao nome original "cidade da paz". Ela será chamada "Paz-da-justiça e glória-da-piedade". Justiça e piedade serão as palavras de ordem dos hassidim, dos piedosos: a observância da lei e o temor de Deus que são a essência do livro do Deuteronômio. 


\section{Conclusão}

Ao ler, mais uma vez, o livrinho de Baruc, este vade-mécum do bom judeu da diáspora, vieram à minha memória duas palavras do segundo testamento.

A palavra de Jesus aos galileus:

Graças te dou, ó Pai, Senhor do céu e da terra, que ocultaste estas coisas aos sábios e entendidos, e as revelaste aos pequeninos. Sim, ó Pai, porque assim te aprouve (Mt 11,25-26).

E a palavra de Paulo aos judeus da diáspora:

Onde está o sábio? Onde está o escriba? Onde está o inquiridor deste século? Porventura não tornou Deus louca a sabedoria deste mundo? Visto como na sabedoria de Deus o mundo não conheceu a Deus pela sua sabedoria, aprouve a Deus salvar os crentes pela loucura da pregação. Porque os judeus pedem sinal, e os gregos buscam sabedoria; mas nós pregamos a Cristo crucificado, que é escândalo para os judeus, e loucura para os gregos. Mas para os que são chamados, tanto judeus como gregos, Ihes pregamos a Cristo, poder de Deus, e sabedoria de Deus. Porque a loucura de Deus é mais sábia do que os homens; e a fraqueza de Deus é mais forte do que os homens (1 Cor 1,20-25).

Creio que baste assim.

O império deve ser enfrentado e não somente suportado. Afinal somos seguidores de um "louco" crucificado que é a verdadeira revelação da sabedoria de Deus e não de um livro. Um livro e uma lei que deixam de ter sentido à luz do único mandamento que o sacrificado nos deixou: amai-vos como eu vos amei (Jo 13,34). Paulo, judeu da diáspora, anunciou a todos esta novidade: Não adulterarás, não matarás, não furtarás, não darás falso testemunho, não cobiçarás; e se há algum outro mandamento, tudo nesta palavra se resume: Amarás ao teu próximo como a ti mesmo. $O$ amor não faz mal ao próximo. De sorte que o cumprimento da lei é o amor (Rm 13,9-10).

Esta é a verdadeira liberdade.

Sandro Gallazzi gallazzi46@gmail.com 